The chapters on seclusion and mechanical restraint were also a revelation to me. The civil-libertarian author considers that grounds for seclusion should be 'limited' to danger to self or others or antisocial behaviour such as undressing in front of other patients on the ward. This, however, is unexceptional compared with the description of the use and regulation of tying patients spread-eagled on the bed for hours or days at a time. The resulting morbidity and mortality is detailed. I have been left wondering which, if any, practices in the UK would cause equal horror in other countries.

Anthony Zigmond Consultant Psychiatrist Seacroft Hospital, Newsam Centre, York Road, Leeds LSI4 6UH, UK

\section{The Neuropsychiatry of Epilepsy}

Edited by Michael Trimble \& Bettina Schmitz. Cambridge: Cambridge University Press.

2002. 350 pp. $€ 39.95$ (hb). ISBN 0521005167

As a clinician working with people who have neuropsychiatric disorders, I approached this book looking for new insights, practical management strategies and an update on the current research. In all three areas the book did not disappoint.

The layout of the chapters is confusing, with separate sections on 'clinical aspects', 'cognitive aspects' and 'non-epileptic attacks' as well as on 'treatment' and 'treatment

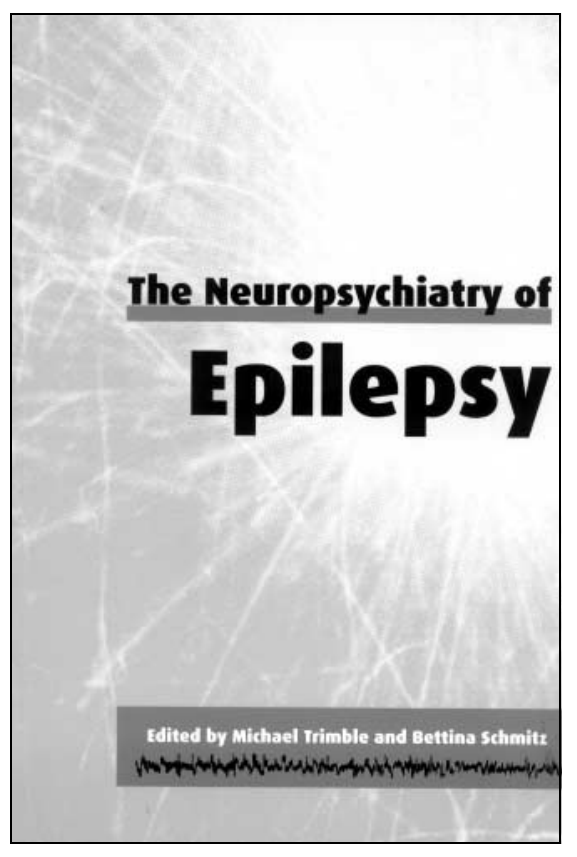

complications'. This gives the book a disjointed feel as a whole (a common feature of multi-authored works). However, many of the individual chapters are excellent. In particular, I enjoyed Frank Besag's chapter on the subtle cognitive and behavioural effects of epilepsy, which provides practical advice on assessment, together with illuminating vignettes. In a chapter on dissociation, Richard Brown gives an excellent description of dissociative phenomena and suggests ways in which different models of this process could be applied to non-epileptic attacks. From a very practical point of view, Trimble $\&$
Hensiek's chapter on the use of psychotropic drugs in epilepsy summarises the current knowledge about both antidepressants and antipsychotics, especially their effect on the seizure threshold (in therapeutic doses and in overdose).

Another problem of multi-author works is that they do not cover the subject area comprehensively. I was keen to find out about inter-ictal psychoses in relation to epilepsy. Unfortunately, this subject is barely mentioned in the book, except in its relationship to post-ictal psychosis (the subject of a whole chapter) and epilepsy surgery (likewise). The concept of forced or paradoxical normalisation is also mentioned only in passing.

Despite this, the book is highly informative on a variety of areas. I would recommend it to anyone practising in the field of epilepsy or neuropsychiatry, including clinicians who work with people with learning disabilities. It would also be a good supplement to Lishman's (1997) Organic Psychiatry for psychiatric trainees revising for the MRCPsych.

In my office, I have three shelves above my desk. The lowest shelf contains books that I access regularly when a clinical question arises. This book will sit on that shelf.

Lishman, W. A. (1997) Organic Psychiatry (3rd edn) Oxford: Blackwell.

Hugh Rickards Consultant in Neuropsychiatry, Department of Neuropsychiatry, Queen Elizabeth Psychiatric Hospital, Birmingham BI5 2QW, UK 